\title{
3D NUMERICAL SIMULATIONS OF WAVES GENERATED BY SUBAERIAL MASS FAILURES. APPLICATION TO LA PALMA CASE*
}

\author{
Stéphane Abadie ${ }^{1}$, Clément Gandon ${ }^{1}$, Stephan Grilli ${ }^{2}$, Richard Fabre ${ }^{3}$, \\ Joëlle Riss ${ }^{3}$, Emmanuel Tric ${ }^{4}$, Denis Morichon ${ }^{1}$ and Stéphane \\ Glockner $^{5}$
}

\begin{abstract}
Three-dimensional (3D) waves generated by landslides are simulated using a three-fluid Navier-Stokes VOF model. With this approach, the interaction between slide and water is implicitly solved. The model capabilities are first tested for benchmark cases featuring rigid body motion. Results are good in two dimensions (2D) and encouraging in 3D. Wave generation by a potential collapse of the Cumbre Vieja Volcano, on La Palma island, is then studied. Stability analyses show that the Cumbre Vieja flank is currently highly stable and that potential slide volumes are likely to be closer to 100 $\mathrm{km}^{3}$, rather than the $500 \mathrm{~km}^{3}$ predicted in earlier studies. Results of the Navier-Stokes model show that waves generated are highly dependent upon the details of slide mechanism and kinematics. In our worst 3D scenario (assuming an inviscid fluid), the initial wavelength is $20 \mathrm{~km}$ and the wave height decrease seems high.
\end{abstract}

\section{INTRODUCTION}

Subaerial mass failures (SuMF) can occur in various environments, such as volcanic islands, fjords, or alpine lakes. Large size SuMFs are known to be potentially tsunamigenic. Numerical models can be developed into powerful tools for natural hazard assessment and mitigation, provided the relevant physics is simulated in their equations. SuMFs, however, are complex phenomena, involving multiple media, strong vertical flows, violent air/water mixing, turbulence, complex slide/water interactions, and typically, intense wave breaking. In such a context, depth-integrated models based on the classical nonlinear shallow water wave approximation, which have proved successful for modelling other type of tsunami generation, cannot be used, and a full NavierStokes (NS) model is the only alternative.

Abadie et al. (2006) and Abadie et al. (2008a,b) recently developed and applied an incompressible NS model, using a VOF interface tracking, to the simulation of SuMFs and resulting wave generation. The computational domain was composed of three fluids : water, air, and the slide, treated as a Newtonian fluid of arbitrarily large viscosity. A penalty method, applied on the stress tensor, was used to prevent deformation in solid-like slides (with very large

1 Laboratoire de Sciences Appliquées au Génie Civil et Côtier, Université de Pau et des Pays de l'Adour, Allée du Parc Montaury, 64600 Anglet, France

2 Dep. of Ocean Engineering, University of Rhode Island, Narragansett, RI 02882, USA

${ }^{3}$ Ghymac, University of Bordeaux I, Av. Des Facultés, 33405 Talence Cedex, France

${ }^{4}$ Geoscience Azur, UMR CNRS-IRD-UNSA-UMPC, France

5 Labor.Trefle - UMR 8508 - Site ENSCPB. 16 Av. Pey-Berland, 33607 Pessac, France

* To appear in Proc. 32nd Intl. Coastal Engng. Conf. (Hamburg, Germany, Sept. 2008). ASCE Publications, 11 pps. 
viscosity). Only applications of this model to two-dimensional (2D) SuMFs were presented in earlier work.

In this paper, we present new validation results for both $2 \mathrm{D}$ and threedimensional (3D) benchmarks, and a 3D application of the model to a case study of Cumbre Vieja's (La Palma, Canary Islands) potential collapse.

\section{BENCHMARK CASES}

One of the objectives of the European project "Tsunami Risk And Strategies For the European Region" (TRANSFER) is to validate and compare different tsunami models against a set of experimental benchmarks, in order to assess their range of validity and thus improve their reliability.

One of these benchmarks is the SuMF experiments by Liu et al. (2005), performed in a 3D large scale flume, in which a rigid wedge moved down a plane surface piercing $1: 2$ slope $\left(26.57^{\circ}\right)$ from an initial state of rest. The motion of the wedge, free surface and run-up were measured at different locations of the flume. Liu et al. (2005) also performed numerical simulations with a NavierStokes free surface VOF model. In these simulations, the motion of the rigid slide was prescribed based on measurements, and thus the interaction between the solid and the water mass was not simulated. These authors reported a good agreement of model results with experimental data.

The first benchmark presented here consisted in testing our model for a simpler 2D case, quite similar to Liu et al. 's (2005). Heinrich (1992) performed a $2 \mathrm{D}$ experiment for a solid wedge sliding down a $45^{\circ}$ slope. Wedge motion and free surface elevation were measured as a function of time. Yuk et al. (2006) simulated this case using a Reynolds-averaged NS VOF model and obtained good agreement with the data by prescribing the slide motion.

Results of applying our model to both these 2D and 3D benchmarks are detailed in the following

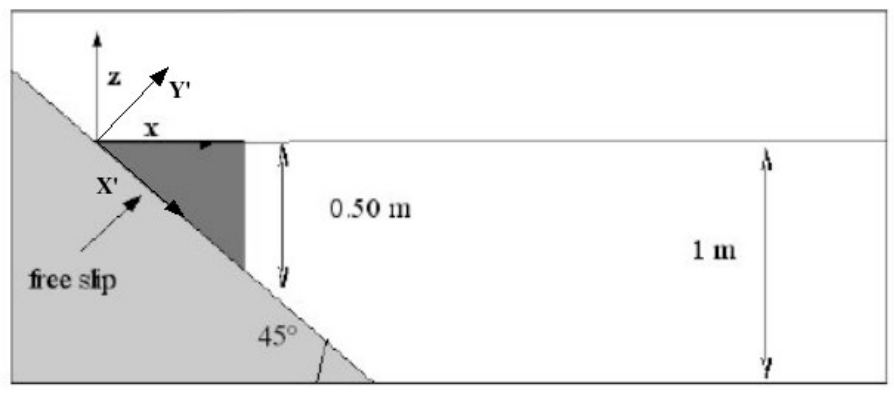

Figure 1 : sketch of Heinrich's experiment

2D Case : Heinrich's (1992) experiment 
In our model, the sliding wedge is represented by a Newtonian fluid of very large viscosity, $\mu=10^{10} \mathrm{~Pa}$.s. By using this high viscosity value, deformation of fluid particles within the slide follows a quasi rigid behavior. Importantly, in our method the multi-phase NS flow model implicitly calculates slide/water interactions and, hence, no external wedge motion is prescribed. Specifically, in the model, both wedge and fluid motion are solved in frame ( $\left.X^{\prime}, Y^{\prime}\right)$ (Fig. 1) so that the bottom boundary of the computational domain corresponds to the incline.
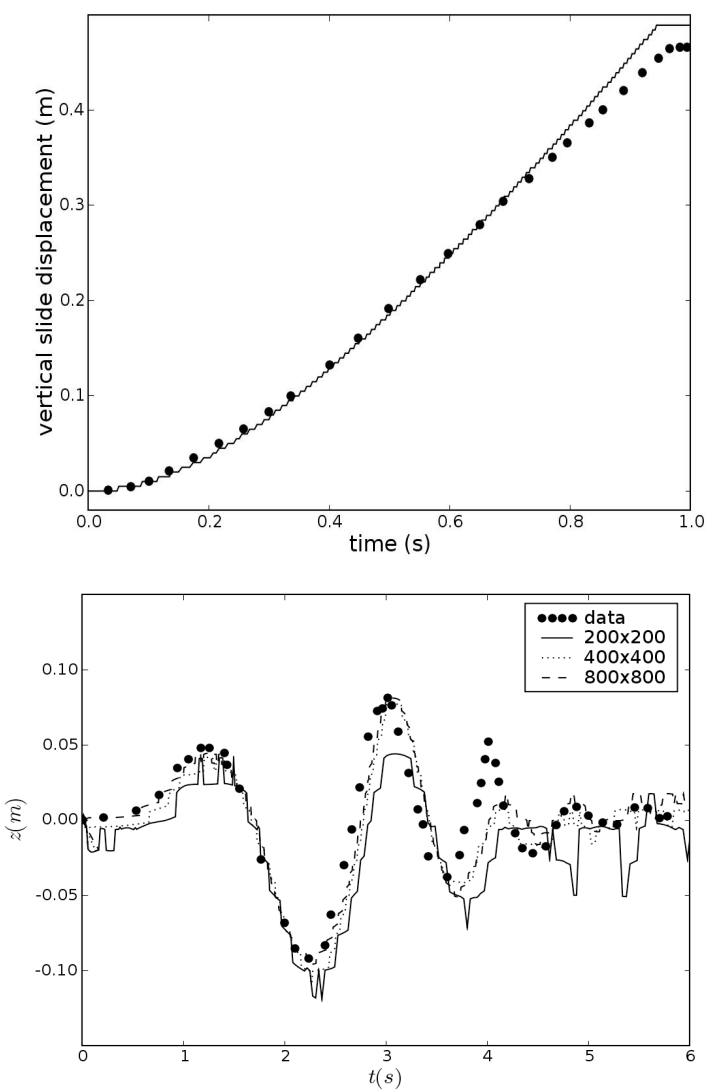

Figure 2 : Model results compared to Heinrich's experimental data (·); top frame : slide vertical displacement versus time, bottom frame : free surface elevation at $x / h=4$, for different meshes.

Figure 2 presents simulation results using different meshes. The top figure shows the vertical displacement of the rigid body obtained with a $400 \times 400$ mesh. Numerical results agree reasonably well with experimental data, 
confirming that solid/water interactions are properly simulated in the model. Accordingly, surface elevation (bottom figure) measured four depths away from the wedge initial location is accurately calculated in the model, at least for the first two waves. The tail of trailing waves is not well described by the model, likely in part due to the fact that the emerged part of the slope was not the same as in Heinrich's experiment. We also note that results are still acceptable even using the coarser resolution, which is encouraging for $3 \mathrm{D}$ future computations.

\section{D case : Liu et al.'s (2005) experiment}

The experiments of Liu et al. (2005) were simulated with our three fluid NS model. Here, the quasi-rigid behavior of the slide was obtained by setting the fluid viscosity to $10^{5} \mathrm{~Pa}$.s, a smaller value than in the earlier $2 \mathrm{D}$ case. [Due to using different linear equation system solver in the model, for 2D and 3D cases, a value of $10^{10} \mathrm{~Pa} . \mathrm{s}$ did not yield convergence of the iterative BICGSTAB solver in $3 \mathrm{D}$ cases.] Due to the lateral symmetry of the experiments, only half the domain was simulated (Figure 3 ). A varying mesh was used in the model, with the finest grid size ( $5 \%$ of the basal wedge length) specified near the initial wedge location. Coulomb friction effects between the solid wedge and the slope are simulated by reducing the intensity of the gravity force applied to the slide. Using this method and comparing model results for slide motion with experimental data, an equivalent Coulomb friction coefficient of 0.16 was found, which agrees well with the range of values reported in Liu et al. (2005).
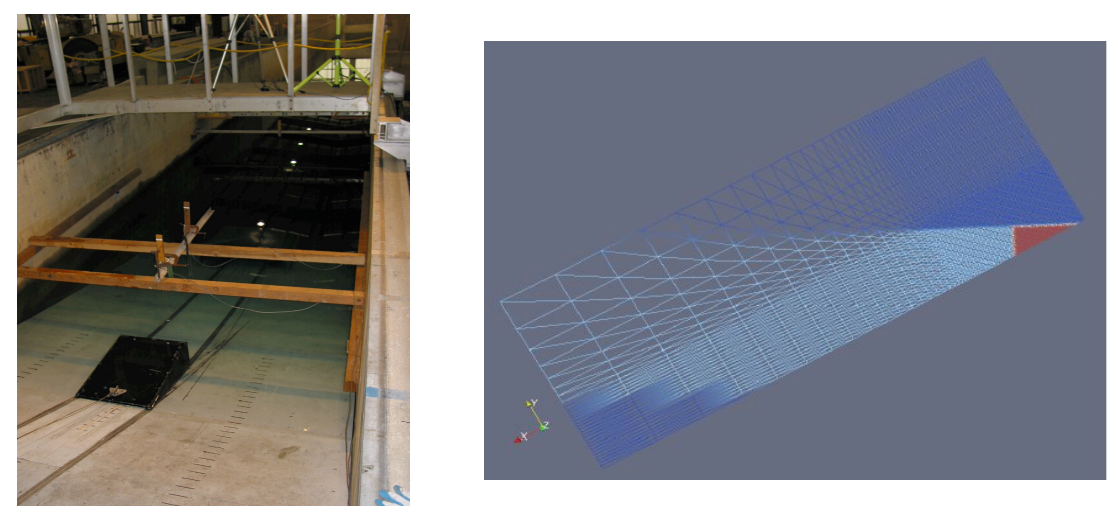

Figure 3 : left frame : picture of Liu et al.'s (2005) experimental set-up; Right frame : irregular mesh used for 3D simulations

Figure 4 shows model results corresponding to experimental run 30 , for an initial wedge submergence of $-0.1 \mathrm{~m}$. The bottom frame confirms that slide motion and thus solid body/water interactions are accurately computed in the model. This is an encouraging result for future $3 \mathrm{D}$ investigations. In the top 
frame, simulated water/air interface elevation at gage 1 (in the plane of symmetry, $1.83 \mathrm{~m}$ from the initial shoreline) also agrees well with free surface measurement. We are planning to supplement these preliminary results, and hence reaching more definitive conclusions as of model accuracy, by performing more detailed comparisons with gages and run-up data, for both runs described in Liu et al.'s benchmark.

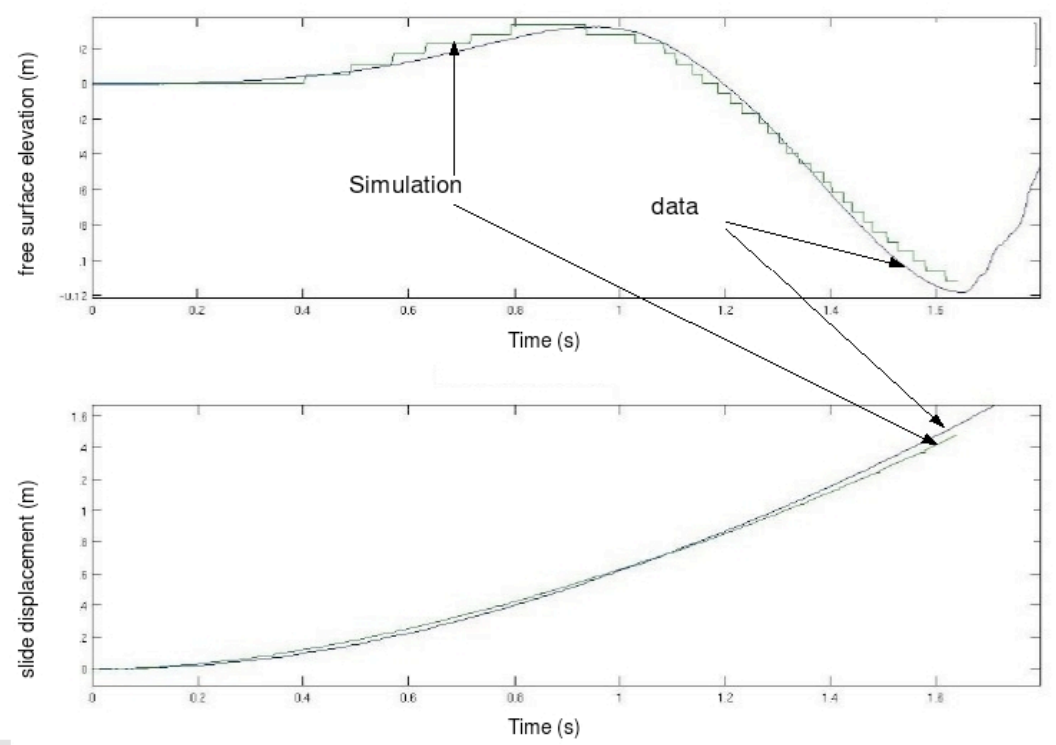

Figure 4 : 3D simulation results compared to experimental data (Liu et al., 2005; Run 30). Top frame : free surface time history at gage 1 ; bottom frame : slide motion.

\section{CASE STUDY : CUMBRE VIEJA VOLCANO}

The potential flank collapse of the Cumbre Vieja volcano on the island of La Palma (Canary Islands) has been the subject of several works in the pas few years. The first, and rather controversial paper, by Ward and Day (2001) concluded with the possibility of the generation of a catastrophic tsunami wave for the entire North Atlantic Ocean basin. Mader (2001) and Pararas-Carayannis (2002) did not support this conclusion, owing to several inconsistencies in the modeling approach, discussed in their papers, but also to the perhaps unrealistic size of the suggested failure. Based on a revised, less catastrophic, failure scenario (Day, personal communication), Perignon (2006) performed simulations with a long wave Boussinesq propagation model, and found much smaller tsunami waves and impact, particularly or the US East Coast. Gisler et al. (2006) used a multiphase compressible NS model to simulate wave 
generation based on the same slide volume hypothesis as in Ward and Day (2001). Their results differed from Ward and Days (2001), in the sense that generated waves had shorter wavelengths and hence would likely cause less impact on distant shores. Based on this tsunami source, Lovholt et al. (2008) recently studied transoceanic wave propagation, using a Boussinesq model owing to the shorter and more dispersive waves generated at the source. As in other reported results, potential impact on distant shores, although significant, was found to be less severe than in the initial work by Ward and Days (2001).

Based on earlier work, it thus appears that a successful simulation of this case study requires : (i) a realistic geologic scenario or the volcano flank collapse; (ii) an accurate multiphase modeling of the subaerial failure and resulting tsunami source; and (iii) a dispersive long wave model to simulate transoceanic propagation, owing to the shorter and more dispersive nature of landslide tsunami waves (e.g., Grilli and Watts, 2005). Within the framework of the TRANSFER project, a three stage study was thus carried out to evaluate the threat posed by La Palma's volcano collapse. First, a slope stability study was performed by research teams at the University of Bordeaux I and Geoscience Azur CNRS (France). Second, based on the likeliest proposed scenario (i.e, slide volume and geometry), NS simulations were carried out with our model, to calculate the features of the wave field close to the generation area (i.e., the tsunami source). Finally, the simulated SuMF tsunami source will be used as input in a Boussinesq tsunami propagation model that has already been used to perform other tsunami case studies, including landslide tsunamis (e.g., Watts et al., 2003; Perignon, 2006; Grilli et al., 2007; Tappin et al., 2008). This latter stage is still ongoing and will be completed in collaboration with teams at the University of Rhode Island and University of Delaware (USA). In this paper, we only present results of the first and second stages of this work.

\section{Slope stability analyses}

The evaluation of the stability of the western flank of La Palma Island's Cumbre Vieja volcano was performed based on known geotechnical properties of the slope, but so far excluding magmatic or seismic parameters. The 2D geometrical model of a potential flank collapse and the location of the failure are inferred from field data and corresponding slope stability simulations made with : (i) a finite difference program that performs a Lagrangian analysis (Slope $($ ) FLAC-2D version); and (ii) a finite element method (ADELI) developed by Chéry and Hassani (2000). The water table is assumed to be located at a $440 \mathrm{~m}$ depth, near the dyke, with a progressively decreasing level towards the shore. The Mohr Coulomb criterion is used.

In Flac/Slope $($, slope factor of safety calculations are performed by progressively reducing the shear strength of the material, in order to reach the failure point. In this study, friction angle $\phi$ and cohesion $c$ of the cliff sequence were progressively reduced. These global investigations allowed us to propose a geologically realistic model for the landslide motion, including velocity and 
volume (width, length and thickness of landslide). The factor of safety $(F)$ value found for the case described is 2.78. [Note Van Berlo 2007, give $F=1.7$ using Plaxis' software with other mechanical parameters.] This indicates that La Palma's western flank is thus likely to be stable under present conditions. Seismicity, however, could provide additional destabilizing forces that are not included in this analysis.

Using ADELI and gradually decreasing material properties, we found $F=1$ for $c=900 \mathrm{KPa}$ and $\phi=9^{\circ}$. The potential failure surface was then identified from the locations of maximum shear strain rates. A global shear zone, more or less parallel to the topography and dipping $24^{\circ}$ westwards, is thus found based on global plastic indicators and areas of maximum shear strain. Identification of a 2D slide cross-section finally allows determining slide volume from field data (width and length of semi-elliptic shape). Following this approach, we find two estimates of landslide volume for the western flank of La Palma : (i) 38 to 68 $\mathrm{Km}^{3}$ for a small collapse scenario; and (ii) 108 to $130 \mathrm{Km}^{3}$ for a major collapse. The landslide is between 600 and 900 meters high. These values are much smaller than those proposed earlier by Ward and Day (2001) $\left(500 \mathrm{Km}^{3}\right)$ or used by Gisler et al. (2006) and Lovholt et al. (2008). Perignon (2006) used $250 \mathrm{Km}^{3}$ based on Day's revised scenario. Note, analyses of earlier collapses of the Cumbre Vieja, from ocean bottom sediment deposits, indicate typical volumes ranging from $50-200 \mathrm{Km}^{3}$ ( with a 100,000 year average periodicity over the past 1 million years (Masson et al., 2006).

\section{Numerical simulations of waves generated by La Palma's slide}

Several 2D simulations were first performed based on slide characteristics (volume, density) obtained in the above slope stability analyses (Figure 5). As before, the slide is represented by a Newtonian viscous fluid, with various viscosity values specified in order to study the maximum wave height dependence on this parameter. Slide Reynolds number is calculated a posteriori using the averaged slide velocity over the generation area as characteristic velocity and the initial slide thickness as characteristic length. The computational domain is $90 \mathrm{Km}$ long and $10 \mathrm{Km}$ high. The mesh is irregular, with 600 cells in the horizontal direction and 200 in the vertical one. Results in Fig. 6 show that both mean slide velocity during wave generation and maximum wave height, strongly depend on slide viscosity. As could be expected, the largest values are obtained when using the lowest slide viscosity. In this worst case scenario, the mean slide velocity reaches $90 \mathrm{~m} / \mathrm{s}$ and initial waves about $1,000 \mathrm{~m}$, with a period of $160 \mathrm{~s}$ and a wavelength of $L=32 \mathrm{Km}$. Such waves are intermediate depth (i.e., dispersive) waves $(L / h=8$ with $h=4 \mathrm{Km})$. With a larger slide volume $\left(12 \mathrm{Km}^{2}\right)$ and an inviscid slide, Gisler et al. (2006) simulated even higher initial waves of about $1,300 \mathrm{~m}$, with a period of $250 \mathrm{~s}$. We also report on Fig. 6 the wave height calculated from the empirical formula given by Huber and Hager (1997), which is based on granular slide experiment and predicts a much lower initial wave of about 400 meters. 


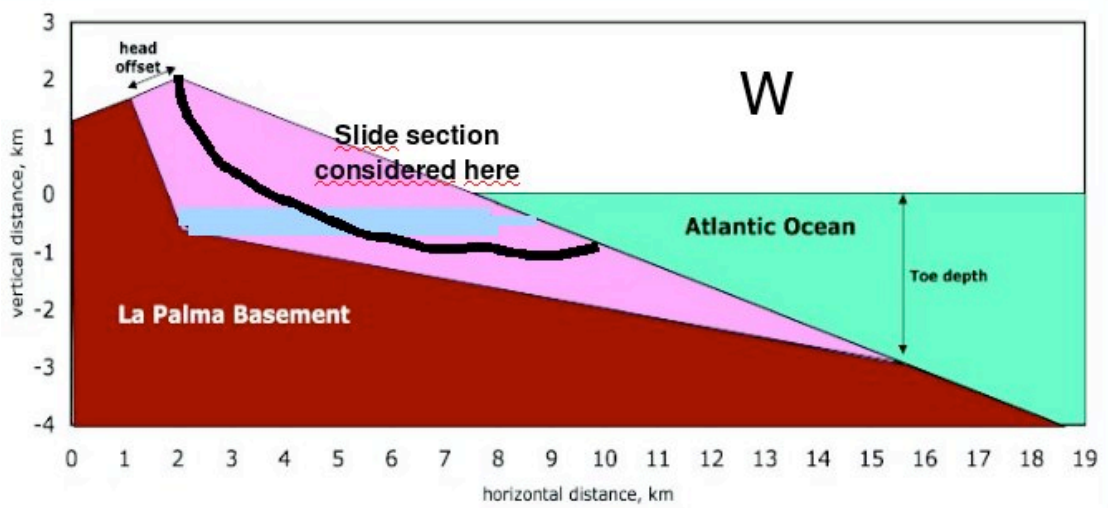

Figure 5 : cross-section of Cumbre Vieja western flank (from Gisler et al., 2006, based on Day, personal communication, 2006). Thre blue (PURPLE ??) area is the 2D slide section considered by Gisler et al. (2006) and the bold black line indicates the slide contour considered in our 2D simulations based on geotechnical analyses (8 $\mathbf{k m}^{2}$ ).

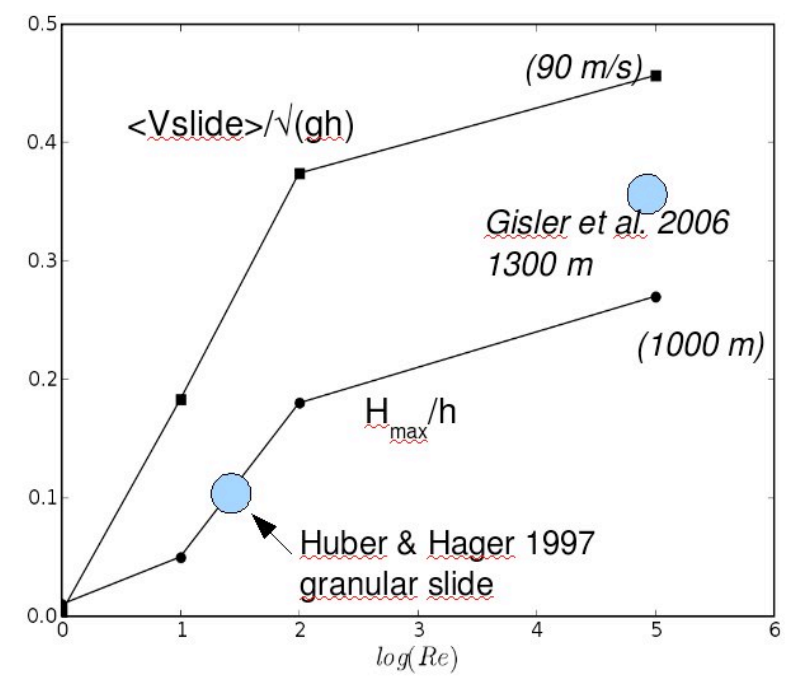

Figure 6 : Results of 2D NS-VOF simulations. The line with black square symbols shows the variation of non-dimensional average slide velocity, and that with black dot symbols, the variation of non-dimensional maximum wave height, both versus the slide Reynolds number. Blue circles show non dimensional wave heights obtained from an extrapolation of Huber and Hager (1997) formula, and Gisler et al. (2006). Some dimensional values of slide average velocity and maximum wave height are also reported. 
A 3D simulation was also performed for this case, which allowed to quantify the effects of lateral spreading on the generated waves. The computational domain is $350 \mathrm{Km}$ long, $200 \mathrm{Km}$ wide and $7 \mathrm{Km}$ high. A coarse irregular mesh of about 800,000 cells was used in this rather preliminary computation. The slide is represented by a half ellipsoid, with major crosssection identical to that of the earlier 2D slide (Fig. 5). The 3D slide volume is about $100 \mathrm{~km}^{3}$. Slide viscosity is set so that its effect is negligible (i.e., quasi inviscid sldie).
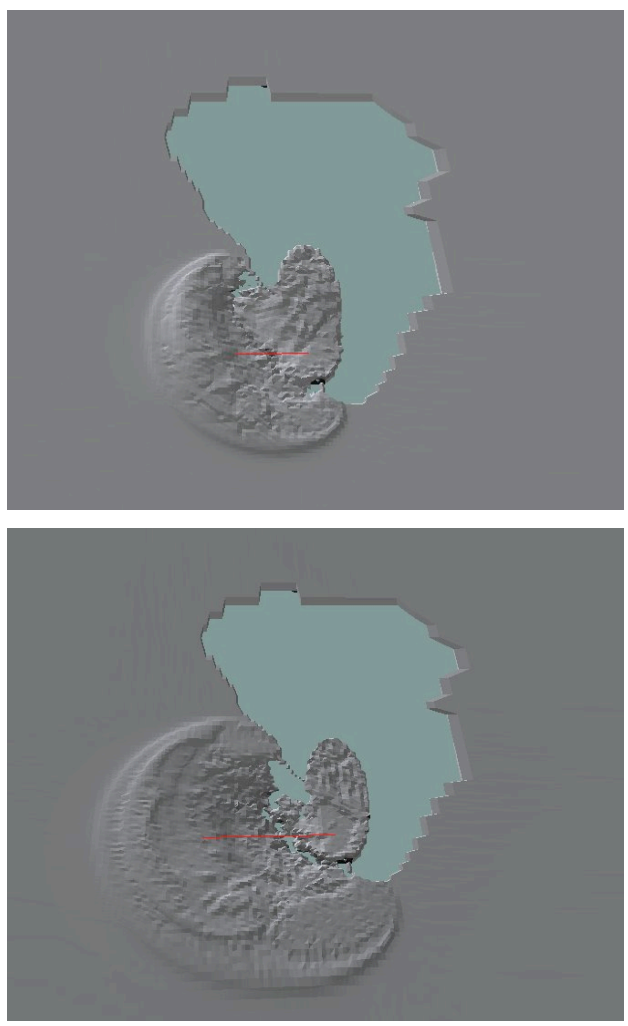

Figure 7 : Snapshots of free surface elevation obtained in the multi-phase 3D NS-VOF simulations of the Cumbre Vieja collapse, at different times. Top frame :

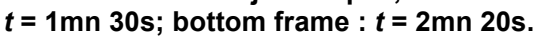

Figure 7 shows the water/air interface elevation at different times during the Cumbre Vieja collapse. A quick assessment of its characteristics shows that generated waves are smaller and shorter than in 2D simulations (at $t=140 \mathrm{~s}, \eta / h$ $=0.15$ compared to 0.20 in $2 \mathrm{D}$, and $L=20 \mathrm{~km}$ in $3 \mathrm{D}$ compared to $32 \mathrm{~km}$ in $2 \mathrm{D}$ ). The wave height attenuation away from the source occurs also quicker, due to lateral energy spreading. Specifically, from $t=140$ and $210 \mathrm{~s}$, the wave height is 
reduced by $1 / 3$ in $3 \mathrm{D}$ and only by $5 \%$ in $2 \mathrm{D}$.

\section{CONCLUSIONS}

In this work, we reported on the simulation of waves generated by subaerial landslides, using a three-fluid Navier-Stokes Volume of Fluid model. Validation cases were presented, based on 2D and 3D experimental benchmarks, followed by a case study of tsunami generation by the flank collapse of the Cumbre Vieja volcano. The following conclusions can be drawn from this study:

- In the $2 \mathrm{D}$ benchmark, waves generated by the rigid sledge can be accurately predicted. In the 3D benchmark, initial simulation results are encouraging but more work is required to better assess the limitations of our approach, particularly related to discretization.

- Regarding the Cumbre Vieja potential collapse, slope stability analyses show that first, the volcano flank appears stable under the hypotheses made in the computations regarding present conditions, and second, volumes concerned by the collapse are likely to be smaller (order $100 \mathrm{Km}^{3}$ ) than formerly predicted.

- Waves associated with the collapse depend strongly on the modeling of the slide motion. In our worst 3D case scenario (inviscid fluid), the wavelength is 20 $\mathrm{Km}$ and the wave height decreases quickly form initial values of order $1 \mathrm{Km}$.

Future work on SuMF tsunami source modeling will consist in improving the grid resolution by performing parallel computing, and using the wave source thus calculated in the $3 \mathrm{D}$ model as input for a Boussinesq propagation model in order to study the far field (transoceanic) effects of the generated tsunami.

\section{AKNOWLEDGMENT}

This work was supported by a grant of the "Tsunami Risk And Strategies For the European Region" (TRANSFER) program, funded by the European Commission, under contract $\mathrm{n}^{\circ} 037058$.

\section{REFERENCES}

Abadie, S, Grilli, S., Glockner, S., 2006. A coupled numerical model for tsunami generated by subaerial and submarine mass failures. In Proc. $30^{\text {th }}$ Intl. Coastal Engng. Conf., San Diego, California, USA. 1420-1431.

Abadie, S, Morichon, D., Grilli, S., Glockner, S., 2008a. VOF/Navier-Stokes numerical modeling of surface waves generated by subaerial landslides. $L a$ Houille Blanche, 1, 21-26.

Abadie, S, Morichon, D., Grilli, S., Glockner, S.. 2008b. A Three fluid model to simulate waves generated by subaerial slandslides. Coastal Engng. (in revision).

Chéry J. and R. Hassani 2000. ADELI user's guide version 1.0: A 2D and 3D finite element software for thermomechanical modeling of geological deformation, http://www.dstu.univ-montp2.fr/PERSO/chery/chery.html,40 pps.

Gisler G., Weaver R., Gittings M.L., 2006. Sage calculations of the tsunami 
threat from La Palma. Science of Tsunami Hazard, 24(4), 288-301.

Grilli, S.T. and P. Watts. 2005. Tsunami generation by submarine mass failure Part I : Modeling, experimental validation, and sensitivity analysis. $J$. Waterway Port Coastal and Ocean Engng., 131(6), 283-297.

Grilli, S.T., Ioualalen, M, Asavanant, J., Shi, F., Kirby, J. and Watts, P. 2007. Source Constraints and Model Simulation of the December 26, 2004 Indian Ocean Tsunami. J. Waterway Port Coastal Ocean Engng., 133(6), 414-428.

Heinirich, P., 1992. Nonlinear water waves generated by submarine and aerial landslides. J. Waterways, Port Coastal and Ocean Eng., 118, 249-.

Huber, A., Hager, W.H. 1997. Forecasting impulse waves in reservoir. Dixneuvième Congrès des Grands Barrage, C31:9931005. Florence, Italy. Commission Internationale des Grands Barrages: Paris.

Liu, P. L.-F., Wu, T.-R., Raichlen, F., Synolakis, C.E. and Borrero, J.C., 2005. Runup and rundown generated by three-dimensional sliding masses. $J$. Fluid Mech., 536, 107-144.

Lubin, P., Vincent, S., Abadie, S. and Caltagirone, J.P., 2006. Threedimensional Large Eddy Simulation of air entrainment under plunging breaking waves, Coastal Engng., 53(8), 631-655.

Lovholt, F. Pedersen, G. and Gisler, G. 2008. Oceanic propagation of a potential tsunami from the La Palma Island. J. Geophys. Res., 113, C09026.

Mader, C.L., 2001. Modeling the La Palma landslide tsunami, Science of Tsunami Hazard, 19, 160-.

Masson, D. G., C. B. Harbitz, R. B. Wynn, G. Pedersen, and F. Løvholt 2006, Submarine landslides processes, triggers and hazard prediction. Philos. Trans. R. Soc., A364, 2009-2039.

Pararas-Carayannis, G. 2002. Evaluation of the threat of mega tsunamis generation from postulated massive slope failure of island stratovolvanoes on La Palma, Canary Islands, and on the island of Hawaii, Science of Tsunami Hazard, 20, 251-.

Pérignon, Y. 2006. Tsunami Hazard Modeling. Senior Engineering Thesis. Department of Ocean Engineering, University of Rhode Island and Ecole Centrale de Nantes, 40 pps.

Tappin, D.R., Watts, P., Grilli, S.T. 2008. The Papua New Guinea tsunami of 1998: anatomy of a catastrophic event. Natural Hazards and Earth System Sciences, 8, 243-266.

Van Berlo, 2007. Simulation of a volcano in Plaxis, Plaxis Bulletin, 21, 3-6.

Yuk D, Yim S.C., Liu P.L.F., 2006. Numerical modeling of submarine massmovement generated waves using RANS model. Computers and Geosciences, 32, 7, 927-935.

Ward S.N., Days S., 2001. Cumbre Vieja Volcano - Potential collapse and tsunami at La Palma, Canary Islands. Geophys. Res. Lett., 28, 397-400.

Watts, P., S. T. Grilli, J. T. Kirby, G. J. Fryer, and Tappin, D. R. 2003. Landslide tsunami case studies using a Boussinesq model and a fully nonlinear tsunami generation model. Natural Hazards and Earth System Sciences, 3, 391-402. 